\title{
Consumo de massas, biodiversidade e fitomelhoramento da banana de exportação 1920 a $1980^{*}$
}

\section{Mass markets, biodiversity and breeding improvements of export bananas}

$1920-1980$ **

\author{
J OHN SOLURI \\ Departamento de História, \\ Carnegie Mellon University \\ Pittsburgh, Pennsylvania,15213 EUA \\ soluri@ hotmail.com
}

RESUMO A exportação de banana, na América, foi constituída sob uma
base genética extremamente limitada: ao longo de setenta anos, uma só
variedade de banana, a Gros Michel, foi praticamente a única a ser ven-
dida nos mercados norte-americanos. Esta variedade produzia grandes
cachos, resistentes ao transporte, e dotados de um sabor e de uma casca
que os consumidores norte-americanos identificavam como pertencentes
a uma banana de qualidade. Entretanto, a Gros Michel também se mostrou

Artigo recebido em: 30/01/2008. Autor convidado.

** Tradução de René Lommez Gomes.

Esse artigo foi publicado primeiramente na Costa Rica, na Revista de Historia, v.44, p.33-66, J ul-Dec.2001, com o título Consumo de masas, biodiversidad y fitomejoramiento del banano de exportación, 1920 a 1980. Agradecemos a autorização desse periódico para a presente tradução para o português. 
muito suscetível a um grande número de patógenos fúngicos, incluindo 0 Mal do Panamá e a Sigatoka. A dinâmica histórica ocasionada, durante a primeira metade do século XX, pela propagação desse fungo, acelerou 0 aumentou dos índices de desmatamento, desestabilizou os sistemas de vida rural, aumentou os riscos à saúde dos trabalhadores do campo, e limitou os rendimentos das principais companhias de comércio de banana. Tais epidemias impeliram o governo britânico e a United Fruit Company a estabelecerem programas de fitomelhoramento, durante a década de 1920, tendo como meta o desenvolvimento de uma banana para exportação, que fosse resistente ao Mal do Panamá. Contudo, a criação de um híbrido que fosse capaz tanto de prosperar nas zonas tropicais, quanto de encontrar aceitação no mercado norte-americano, se mostrou uma tarefa de difícil realização. A história dos programas de melhoramento revela uma das principais contradições da agricultura do século XX: os mesmos processos de produção massificada, que tendem a reduzir a diversidade biológica a nível local e regional, permaneciam dependentes do acesso a de um banco genético "global", para manter níveis lucrativos de produção.

Palavras-chave banana, consumo em massa, biodiversidade

ABSTRACT The export banana industry in Latin America and the Caribbean developed on a very narrow genetic base: a single variety, the Gros Michel, was the only banana variety mass marketed in the United States for at least seventy years. The Gros Michel variety produced large fruit bunches, shipped well, and possessed a flavor and peel color that North American consumers came to recognize as a "quality" banana. The variety was also susceptible to a number of fungal pathogens including Panama disease and Sigatoka. The historical dynamic provoked by the spread of fungal pathogens during the first half of the twentieth century accelerated rates of deforestation, destabilized rural livelihoods, increased occupational health risks for farm workers, and lowered profits of major banana companies. The epidemics prompted both the British government and the United Fruit Company to establish banana breeding programs during the 1920s with the goal of developing an export variety with resistance to Panama disease. However, breeding a variety that possessed both disease resistance and marketability proved to be a difficult task. Both the British and United Fruit sent teams of botanists to comb the world's tropical regions in search of new varieties for their breeding programs. The history of export banana breeding programs reveals one of the principle contradictions of twentieth-century agriculture: the same processes of mass production that tend to reduce biological diversity on local and regional levels depend upon access to a global "genetic bank" in order to maintain profitable production levels.

Key words banana, mass market, biodiversity 


\section{Introdução}

Em maio de 1927, dezenas de posseiros invadiram um terreno próximo à aldeia de La Masica, na Costa Norte de Honduras, propriedade da Standard Fruit Company, de Nova Orleans. Anteriormente, esse terreno havia sido um bananal, abandonado pela Companhia ao ser infestado com o Mal do Panamá. J acobo P. Mungía explicava, em uma carta dirigida ao Presidente de Honduras, Miguel Paz Barahona, que os posseiros estavam tentando colaborar com a Companhia, e não lutar contra ela: "Estes homens [os posseiros] dizem que querem colher esta banana resistente [ao Mal do Panamá], e que se a Companhia encontrar um mercado para ela, eles venderão, com prazer, a sua produção". ${ }^{1}$ Mungía anexou uma petição à carta, contendo os nomes de 108 indivíduos que expressaram seu desejo de trabalhar "independentemente", cultivando uma variedade de banana denominada Lakatán.

A primeira vista, não há nada de extraordinário nesse incidente: lutas entre proprietários e posseiros foram comuns nas zonas exportadoras de banana, durante o século XX. ${ }^{2}$ Entretanto, a petição de La Masica se mostra relevante, pois nos lembra que a terra não é o único recurso biológico cujo acesso se faz necessário aos agricultores. As plantas propriamente ditas - neste caso, bananeiras resistentes - são também vitais; um ponto tão óbvio que passaria despercebido pela maioria dos historiadores.

A petição citada também identifica outro elemento vital na vida dos produtores de banana para exportação: o mercado. Historiadores da economia escreveram extensamente sobre os ciclos de altos e baixos que caracterizaram as economias exportadoras da América Latina. Contudo, não centraram sua atenção no entendimento de como o processo de mercantilização afetou os recursos biológicos que constituíram a base das tendências de exportação. ${ }^{3} 0$ presente artigo oferece uma interpretação da indústria bananeira a partir de uma ótica que integra a história econômica à história ecológica. Infelizmente, as evidências revisadas revelam muito pouco sobre como os agricultores de pequena escala, tais como os posseiros de La Masica, cultivaram a banana. Em contraste, há abundância de fontes, publicadas e inéditas, que nos permitem examinara história dos programas institucionais de fitomelhoramento da banana, e, assim, explorar as conexões históricas existentes entre a produção de banana para exportação, a biodiversidade e o consumo em massa, durante o século XX.

1 Tegucigalpa. Archivo Nacional de Honduras. MUNGIA, Jacobo P. Esparta. Al Presidente Miguel Paz Barahona, Tegucigalpa, 16 de mayo 1927. Legajo, Correspondencia particular, año 1921.

2 Para exemplos de conflitos acerca da terra, ver LEGRAND, Catherine. Frontier expansion and peasant protest in Colombia, 1850-1936. Albuquerque: University of New Mexico Press, 1986; e, SOLURI, J ohn. People, plants, and pathogens: the eco-social dynamics of export banana production in Honduras, 1875-1950. Hispanic American Historical Review, n.80, p.463-501, 2000.

3 Para uma discussão aprofundada das economias de exportação, e debates historiográficos a elas relacionados, ver WELLS, Allen; TOPIK, Steve. The second conquest of Latin America. Austin: University of Texas Press, 1998. 
A exportação de banana, na América, foi constituída sob uma base genética extremamente limitada: durante setenta anos, uma só variedade de banana, a Gros Michel, foi praticamente a única a ser vendida nos mercados norte-americanos. Esta variedade produzia grandes cachos, resistentes ao transporte, e dotados de agradáveis propriedades estéticas. Entretanto, a Gros Michel também se mostrou muito suscetível a um grande número de patógenos fúngicos, incluindo o Mal do Panamá e a Sigatoka. A dinâmica histórica ocasionada, durante a primeira metade do século $X X$, pela propagação desses patógenos, aumentou os índices de desmatamento, desestabilizou os sistemas de vida rural, aumentou os riscos à saúde dos trabalhadores do campo, e limitou os rendimentos das principais companhias de comércio de banana. ${ }^{4}$ Como afirmaram Rowe y Richardson, "não há produto que ilustre melhor os perigos inerentes ao cultivo de monoclones". ${ }^{5}$ A epidemia do Mal do Panamá incitou o governo britânico e a United Fruit Company a estabelecerem programas de fitomelhoramento, durante a década de 1920, tendo como meta o desenvolvimento de uma banana para exportação que fosse resistente a ele. Contudo, a criação de um híbrido capaz tanto de prosperarnas zonas tropicais, quanto de encontrar aceitação no mercado norte-americano, se mostrou uma tarefa de difícil realização. A história dos programas de melhoramento revela uma das principais contradições da agricultura do século XX: os mesmos processos de produção massificada, que tendem a reduzir a diversidade biológica a nível local e regional, permaneciam dependentes do acesso a de um banco genético "global", para manter níveis lucrativos de produção.

\section{A difusão da Musa e o início do comércio de exportação caribe- nho}

Existem de trinta a quarenta espécies de Musa, incluindo a Musa acuminata Colla (AA) e a Musa balbisiana Colla (BB), as duas espécies das quais teriam se originado a maioria das variedades comestíveis de banana, conforme se crê. ${ }^{6}$ Os cientistas concordam que o cultivo da banana se deu, primeiramente, no Sul e Sudeste da Ásia, onde uma seleção, levada

4 Ver MARQUARDT, Steve. Green Havoc: Panama disease, environmental change and labor process in Central America. American Historical Review, n.106, 2001; SOLURI, J ohn. People, plants, and pathogens; TUCKER, Richard. Insatiable appetite: the United States and the ecological degradation of the tropical world. Berkeley: University of California Press, 2000.

5 ROWE, Phillip; RICHARDSON, D.L. Breeding bananas for disease resistance, fruit quality, and yield. La Lima/Honduras: Tropical Agriculture Research Services, 1975, p. 4.

6 Note-se que, durante a primeira metade do século XX, os cientistas distinguiam a Musa em M. paradisíaca (a banana da terra) da M. sapientum ("banana de sobremesa"). J ONES, David R. (ed.) Diseases of banana, abacá, and enset. Nova York: CABI Publishing, 2000, p.1-2.

N.T.: em espanhol, a banana da terra recebe o nome de plátano e, em inglês, plantain. Ela é menos doce e usada geralmente para cozinhar. O outro tipo, de frutos mais macios e doces, é chamado de banana de sobremesa, ou seja, comestível ao natural, como a banana prata, por exemplo. 
a cabo pelos humanos, produziu a eliminação das sementes nos cultivares diplóides (AA) e, mais tarde, nos cultivares triplóides (AAA). Os agricultores do Sudeste Asiático foram, também, os primeiros a cruzar cultivares $M$. acuminata $(A A)$ com M. balbisiana (BB), produzindo plantas híbridas ( $A B$ e $A A B)$, que tendiam a ser mais resistentes e tolerantes à seca, que as variedades $M$. acuminata puras.

Norman W. Simmonds, perito britânico em bananas, propunha a teoria de que as primeiras bananas comestíveis teriam aparecido na Malásia. Mas, estudos mais recentes, baseados na analise do DNA, sugerem que os ancestrais das atuais variedades comestíveis de banana foram inicialmente cultivados em Papua Nova-Guiné e nas Filipinas. ${ }^{7}$ Partindo destas regiões, a banana se difundiu até a Índia, África e Polinésia.

É provável que algumas variedades de banana tenham chegado ao continente africano há 2000 anos. Quando os portugueses chegaram à costa atlântica da África, o cultivo da banana era comum na região. Marinheiros portugueses introduziram a banana nas Ilhas Canárias, em princípios do século XV. Alguns estudiosos consideram também que a banana chegou à América do Sul por via de viajantes polinésios. ${ }^{8}$ Durante os séculos XVI e XVII, a banana se propagou nos trópicos americanos: nas zonas açucareiras do Brasil e do Caribe, os escravos cultivaram bananas, que desempenharam um importante papel na sua improvisada cozinha.

Até o princípio do século XIX, a variedade Gros Michel (Musa acuminata) não aparece nos registros históricos. Em 1830, um botânico francês, J ean Franço is Pouyat, observou o crescimento dessa planta, na Martinica. Pouyat levou um espécime para a J amaica, onde lidava com uma plantação de café. A variedade se difundiu pela ilha, onde era conhecida como Banano de Martinica ou Banano Pouyat. ${ }^{9}$ Do Caribe, a variedade se disseminou pela América Central, e mais adiante. Em 1892, oficiais colombianos coordenaram uma importação de Gros Michel, da J amaica. E, não é de se duvidar que, na mesma época, a Gros Michel também tenha se disseminado através de vias extra-oficiais, dada a intensidade da migração de trabalhadores da J amaica até 0 istmo centro-americano. ${ }^{10}$

7 SIMMONDS, Norman W. The evolution of bananas. Londres: Longman's, 1962, p.146; J ONES David R. (ed.) Diseases of banana, abacá, and enset, p.27.

8 Para uma discussão recente acerca dessas evidências, ver LANGDON, Robert. The banana as a key to early American and Polynesian History. J ournal of Pacific History,n.28, p.15-35, 1993.

9 RODIGUEZ, D.W. Bananas: An outline of the economic history of production and trade with special reference to J amaica. Kingston: The Government Printer, 1955, p.11-12.

10 Sobre as migrações das Índias Ocidentais para as zonas bananeiras da América Central, ver CHOMSKY, Aviva. West indian workers and the United FruitCompany in Costa Rica, 1870-1940. Baton Rouge: Louisiana State University Press; PUTNAM, Lara Elizabeth. Public women and one pant men: labor migration and the politics of gender in Caribbean Costa Rica, 1870-1960. University of Michigan, 2000 (Tese de Doutorado); ECHEVERRI-GENT, Elisavinda. Forgotten workers: British West Indians and the early days of the banana industry in Costa Rica and Honduras. J ournal of Latin Americ an Studies, n.24, p.275-308, 1992. 
No início do século XX, a Gros Michel foi a variedade mais procurada no crescente comércio de banana desenvolvido entre o Caribe e os Estados Unidos. ${ }^{11}$ Os transportadores navais davam preferência à Gros Michel, por sua resistência aos rigores da viagem, devido à grossura de sua casca e ao caráter compacto de seus cachos. Sob condições agrícolas favoráveis, a planta produzia altos rendimentos, com grandes frutas amarelas, cujo sabor era um grande atrativo entre os consumidores dos Estados Unidos. Ainda que, no final do século XIX, outras classes de bananas tivessem esporadicamente chegado aos mercados norte-americanos, foi em torno da variedade Gros Michel que as transportadoras, os trabalhadores e os consumidores formaram sua idéia acerca do que era uma banana de qualidade.

\section{Produção em massa, transformação ambiental e o Mal do Pa- namá}

Na década de 1890, os pequenos produtores e embarcadores pioneiros no comércio de banana, encontraram-se em meio a uma crescente competição com cultivadores e transportadoras navais de grande peso financeiro. Em 1899, umas doze companhias se uniram para formar a United Fruit Company, iniciando uma era de produção para a exportação, caracterizada pelas plantações em larga escala, expansão das redes ferroviárias, além do crescimento dos índices de uso de recursos. Entre 1892 e 1911, as importações de banana, nos Estados Unidos, aumentaram de 12 milhões de cachos para quase 4 milhões, seguindo-se de um leve decréscimo nas importações, relacionado com as restrições ao embarque, provocadas pela Primeira Guerra Mundial. As importações subiram até 65 milhões de cachos, em 1929.

Em certas regiões, os pequenos produtores continuaram desempenhando um papel vital, mas três companhias norte-americanas (a United, a Standard e a Cuyamel Fruit Company) dominaram o comércio, controlando os trens de ferro, as transportadoras navais e o mercado. Em 1926, a United Fruit possuía 650.000 hectares de terra, incluindo 70.000 hectares de plantações de banana em atividade. ${ }^{12}$ Virtualmente, cada um destes hectares não continha outra coisa senão clones de Gros Michel e ervas.

A dramática expansão do cultivo de banana para exportação transformou uma porção significativa das úmidas planícies tropicais de baixa altitude, que se estendem ao largo da costa caribenha, indo da Guatemala à Colômbia. Milhões de trabalhadores botaram abaixo os bosques, drenaram

11 J ENKINS, Virginia Scott. Bananas: an American story. Washington, D.C.: Smithsonian Institute, 2000, p.14-15; HIGGINS, J.E. The banana in Hawaii. Hawaii Agricultural Experiment Station, Bulletin n.7, Honolulu: Hawaiian Gazette Company, p.42, 1904.

12 CUTTER, Victor M. Caribbean tropics in commercial transition. Economic Geography, n.2, p.494-507, 1926. 
as terras úmidas, e construíram uma infra-estrutura, incluindo facilidades portuárias, trens, acampamentos operários, áreas de drenagem e canais de irrigação.

A rápida transformação dos ambientes tropicais das terras baixas da América Central gerou o contexto agro-ecológico no qual emergiu o Mal do Panamá. 0 patógeno de solos, associado à enfermidade (Fusarium oxysporum f. cubense), penetrava primeiro na estrutura das raízes para, eventualmente, dirigir-se à folhagem, onde fazia com que as folhas parassem de funcionar. Em casos mais severos, a planta infectada caía. Desde muito cedo, em torno da década de 1890, relatos de sintomas semelhantes circularam pelo Panamá. Na década de 1910, a enfermidade avançou fortemente pela Costa Rica e Suriname. Epidemias similares apareceram em Honduras e na Guatemala, na década de 1920, e na J amaica, na década de 1930.

Sendo densamente plantados, os monocultivos de clones de Gros Michel possuíam poucas barreiras genéticas ou de relevo, capazes de conter a difusão do fungo..$^{13} \mathrm{O}$ patógeno se deslocava através dos movimentos das cepas utilizadas para o plantio, das águas de irrigação e drenagem, de animais de carga e da migração de trabalhadores.

Os esforços iniciais para controlar o patógeno, através de quarentenas e da destruição das plantas enfermas, foram, em geral, ineficazes. Em 1916, a United Fruit contratou um pesquisador do Massachussets Institute of Technology, Samuel Prescott, para dirigir um estudo de solos, na Colômbia, Costa Rica, Guatemala, Honduras e J amaica, com a intenção de encontrar indícios acerca de como a fisiografia e/ou a constituição química dos solos afetava o patógeno. No entanto, Prescott não obteve sucesso em identificar nenhuma correlação entre as características dos terrenos e a incidência do mal. Também realizou experimentos com vários compostos químicos, para ver se conseguia matar ou controlar o patógeno, mas nenhum de suas tentativas alcançou resultados que pudessem ser aplicados em larga escala. ${ }^{14} \mathrm{Em} \mathrm{1923,} \mathrm{um} \mathrm{cientista} \mathrm{da} \mathrm{United} \mathrm{Fruit} \mathrm{relatou} \mathrm{que} \mathrm{vinte}$ anos de investigação e tratamentos, "através de todos os métodos usuais empregados nas práticas de controle de enfermidades", haviam fracassado em conter a epidemia. ${ }^{15}$

13 Para uma discussão geral da correlação entre a densidade de plantas e incidência da enfermidade, ver MUNDT, Christopher C. Disease dynamics in agroecosystems. In: CARROLL, C.R.; VANDERMEER, J ohn; ROSSERT, Peter. (eds.) Agroecology. Nueva York: McGraw-Hill, 1990, p.263-299.

14 PRESCOTT, Samuel. Report on the examination of tropical soils. United Fruit Company, julho 1918; PRESCOTT, Samuel. Diseases of the banana. United Fruit Company Research Bulletin, n.2, janeiro de 1917. Cópias destes relatórios se encontram na biblioteca da Fundación Hondureña de Investigación Agrícola (doravante, FHIA), em La Lima, Honduras.

15 J OHNSTON, J ohn. Mosaic disease of sugarcane in 1923, diseases and pests of the banana. United Fruit Company, 1923, p.9. 
Já em 1910, alguns cientistas argumentavam que a solução, a longo prazo, para os problemas colocados pela enfermidade do Panamá residia na descoberta de uma variedade de banana resistente ao patógeno. Um pesquisador norte-americano, radicado em Cuba, recomendou o cultivo de Banano chino (um cultivar Cavendish), uma variedade cultivada e comercializada na Ásia, Havaí e nas Ilhas Canárias. ${ }^{16}$

Neste mesmo ano, a United Fruitpôs à disposição do governo holandês do Suriname uma variedade conhecida como Congo (grupo Cavendish). Contudo, apenas uma modesta quantidade de banana Congo chegou ao mercado norte-americano, antes que a United Fruit informasse ao governo holandês de que a variedade não era comercializável, devido à sua curta durabilidade e a sua tendência a amadurecer de maneira irregular. ${ }^{17} \mathrm{~A}$ experiência do Suriname se repetiria, na década seguinte, na América Central e no Caribe. Companhias exportaram pequenas quantidades de banana Lacatán (grupo Cavendish), durante a década de 1920, mas a variedade não obteve aceitação no mercado. ${ }^{18}$

Em 1924, um pesquisador da J amaica relatou esforços realizados para o plantio de outros cultivares Cavendish, incluindo o Bumulan, Robusta e Bout Rond. ${ }^{19}$ No entanto, as primeiras tentativas de se encontrar um substituto para a Gros Michel não obtiveram êxito, pois as expectativas do mercado popular norte-americano haviam se formado em torno das características dessa variedade de banana. Um sem-número de variedades de Musa, presentes nas zonas tropicais, era inexistente para as mentes da maioria dos agentes de transporte, distribuidores e consumidores. A tendência do mercado de massa à simplificação, e sua tentativa de reduzir as frutas a mercadorias uniformes, haviam determinado, junto com a biologia da banana, a forma e o direcionamento do cultivo de banana, no século XX.

16 MCKENNY, R.E.B. The Central American banana blight. Science, n.31, p.750, 13 de maio de 1910.

17 FAWCETT, William. The banana: its cultivation, distribution, and commercial uses. Londres: Duckworth and Co., 1921 [1913], p.230-234.

18 Os cachos de banana Lacatán não amadureciam da mesma forma que os da fruta Gros Michel. Além disto, a Lacatán era suscetível a um fungo que causava o apodrecimento do talo e provocava o desprendimento das frutas, que caíam no chão dos quartos de maturação ou da tenda em que se encontrava o produto. Note-se que as bananas viajavam até os Estados Unidos em cachos. A separação das frutas e o empacotamento em caixas não se davam no local de produção, até a década de 1950. Sobre as experiências com a Lacatán, pela Cuyamel Fruit Company, ver: United States National Archive, U.S. Foreign Agricultural Service, "Narrative reports, 1904-1939", Entry 5, Box 343, Folder "Fruits". FOX, Ray, Cónsul de Estados Unidos en Puerto Cortés. Report on commerce and industry for the year and quarter ended December 1925, 10 de febrero de 1926. Para os problemas da Standard Fruit Cia. E a comercialização da Lacatán ver: Revista del archivo y de la biblioteca nacional de Honduras, $n^{\circ} .2$, p.423, junho de 1931; SEÑOR ORDÓÑEZ, P. Asistente de Secretario de Desarrollo y Obras Públicas, Agricultura y Trabajo, 3 de julio 1926, Archivo de la Gobernación de Atlántida (La Ceiba), Libro copiador de cartas 1926; HORD, H.H.V. The conversion of Standard Fruit Company banana plantations in Honduras from the Gros Michel to the Giant Cavendish Variety. Tropical Agriculture, n.43, p.269-275, outubro de 1966.

19 ASHBY, S.F. Bananas resistant to wilt (Panama disease). Tropical Agriculture, n.1, p.172-17, 1924. 


\section{Programas institucionais de fito-melhoramento, 1920-1940}

Após um giro pelas Honduras Britânicas e pela Guatemala, em 1920, um oficial do Imperial Department of Agriculture britânico, citando o problema do Mal do Panamá, solicitou o desenvolvimento maiores pesquisas sobre a banana, incluindo experimentos em fitomelhoramento. Dois anos mais tarde, o governo britânico fundou o West Indian Agricultural College, em Trinidad (mais tarde rebatizado Imperial College of Tropical Agriculture). Em 1923, E.E. Cheesman se uniu a esta Faculdade e, de imediato, iniciou um programa de fitomelhoramento de bananas. E, em 1924, os britânicos estabeleceram, na J amaica, um segundo programa de investigação. Contudo, o banco reprodutivo empregado nestes experimentos dependia de materiais mandados pelos oficiais coloniais britânicos, instalados em várias partes dos trópicos.

Já na década de 1920, foram levadas a cabo duas expedições de coleta de espécimes, na Ásia, como parte do esforço para controlar o Mal do Panamá. ${ }^{20} \mathrm{Na}$ mesma década, a United Fruit Company também iniciou, no Panamá, experimentos de melhoramento de banana, empregando variedades trazidas da Ásia, Cuba e América Central. A maior parte do material reprodutivo procedia das viagens de coleta feitas pelo cientista norte-americano Otto A. Reinking, entre 1921 e $1927 .^{21}$

A primeira geração de produtores científicos que se lançou à experimentação contava com um conhecimento muito limitado sobre citologia, genética e taxonomia do gênero Musa. ${ }^{22}$ Contudo, os pesquisadores estavam conscientes de uma de suas características fundamentais, partilhada tanto pela Gros Michel, como pelas outras variedades de banana: as plantas eram partenocárpicas, ou seja, não precisavam ser fertilizadas por pólen para produzir frutos. 0 resultado era que o fruto tendia a não ter semente, uma característica provavelmente selecionada pelos cultivadores humanos, durante 0 transcurso de séculos. 0 fato da polpa da banana não possuir sementes também teria aumentado a popularidade de seu consumo.

Entretanto, a partenocarpia impunha um desafio aos cultivadores, que lutavam para obter sementes e pólen da relativamente infértil Gros Michel. As tentativas de fito-melhoramento da banana só foram possíveis graças ao fato de que as plantas de Gros Michel podiam ser induzidas a gerar sementes, em pequenas quantidades, usando pólen de bananas "silvestres", que tinham sementes. Todavia, os níveis de fertilidade permaneciam extremamente baixos.

20 HOWES, F.N. The banana in some tropical Eastern Countries - its forms and variations. Kew Bulletin of Miscellaneous Information, p.305, 1928.

21 ROWE, Phillip; RICHARDSON, D.L. Breeding bananas for disease resistance, p.7-8.

22 SHEPHERD, K. Banana research at ICTA. Tropical Agriculture, n.51, p 482, 1974. 
A descrição feita por Claude Wardlaw, em 1935, dos experimentos de cruzamento levados a cabo no Imperial College, durante a década de 1920, demonstra o desafio representado pela biologia da banana para os cientistas. ${ }^{23}$ Tentativas de polinização foram levadas a cabo com seis variedades diferentes de banana, incluindo a Gros Michel. Variedades comestíveis foram cruzadas "quando possível", mas, devido à sua pequena produção de pólen, muitos dos cruzamentos foram feitos com duas espécies produtoras de sementes. Umas 20.000 flores polinizadas produziram menos de 200 sementes, das quais cinqüenta se encontravam vazias. As sementes restantes vinham de somente duas variedades - a Gros Michel e a Silk (AA) -, e, em ambos os casos, elas haviam resultado da polinização com uma variedade dotada de semente. Dessas, somente dezessete sementes germinaram, e unicamente cinco sobreviveram até produzir fruta. Portanto, os primeiros trabalhos de fitomelhoramento da banana foram tediosos, custosos e cheios de incertezas.

O programa britânico adotou três estratégias para buscar a resistência às enfermidades: cruzamentos repetidos do triplóide Gros Michel (de 33 cromossomos) com diversos diplóides masculinos resistentes (de 22 cromossomos); cruzamentos repetidos de pais masculinos específicos, com vários triplóides alternativos; e o retrocruzamento dos tetraplóides híbridos (de 44 cromossomos) com os pais. Só a primeira estratégia teve êxito em produzir progênie potencialmente detentora do genótipo requerido (ou seja, resistência ao Mal do Panamá), e do fenótipo desejado (características de comercialização similares às da Gros Michel). ${ }^{24}$ Os diplóides tendiam a ter resistência ao fungo, mas, freqüentemente a fruta não se aproximava à da Gros Michel. Por isso, na década de 1940, o melhoramento dos diplóides se converteu em uma prática padrão, e este enfoque dominaria a reprodução seletiva da banana, durante o século XX.25

No princípio da década de 1930, os fitomelhoramentos do Imperial College criaram duas variedades promissoras, a I.C.1 e a I.C.2 que, após seis anos de testes, provaram ser resistentes ao Mal do Panamá. ${ }^{26}$ Dizia-se que o comportamento da I.C.1, durante o amadurecimento, era similarà da Gros Michel. O pesquisador britânico Claude Wardlaw descreveu outras de suas características importantes: "A cor, ao estar madura, era excelente, e 0 sabor, prazenteiro, embora, provavelmente, fosse 'gosto adquirido' ao passo

23 WARDLAW, Claude W. Diseases of the banana. Londres: MacMillan and Company, 1935, p.116.

24 Os pesquisadores atribuíram o fato a uma anomalia genética: quando cruzada com diplóides, a Gros Michel não passava pela meiose normal, a menos que se contribuísse com um gameta triplóide não reduzido. Por outro lado, os polinizadores diplóides sofriam meiose, gerando tetraplóides híbridos. ROWE, Phillip. Breeding bananas and plantains. Plant Breeding Reviews, n.2, p.140, 1984.

25 ORTIZ, R.; FERRIS, R.S.B.; VUYLSTEKE, D.R. Banana and Plantain Breeding. In: GOWAN, Simon. (ed.) Bananas and plantains. Londres: Chapman and Hall, 1995, p.112-113.

26 WARDLAW, Claude W. Diseases of the banana, p.116. 
que a textura fosse notavelmente delicada". ${ }^{27}$ Q uanto às características para o transporte, as suas pencas apresentavam maior resistência a choques e a danos mecânicos, além de apresentarem simetria entre os cachos de forma "similar à Gros Michel, permitindo, portanto, o fácil armazenamento, sob as usuais condições de comércio". A maior 'desvantagem comercial' era que a fruta ocasionalmente produzia sementes, quando cultivada sob as "condições ordinárias dos campos de cultivo".

A afirmação de Wardlaw revela até onde o fenótipo da Gros Michel havia determinado os padrões aceitos para a banana de exportação. Frutas híbridas, cuja forma, cor, textura, sabor e durabilidade não se aproximaram o suficiente das bananas Gros Michel não foram consideradas aptas para a produção comercial, durante a primeira metade do século XX. Não é surpreendente, então, que o I.C.2, com sua fruta relativamente pequena, cachos irregulares, e textura e sabor "inferiores", não encontrasse uma ampla aceitação no mercado.

Um boletim da United Fruit, de 1929, revela que os objetivos da Companhia diferiam muito pouco do programa da equipe britânica de cientistas. 0 autor do boletim, notando uma contínua inabilidade na busca de uma cura prática para o Mal do Panamá sob "as condições de cultura existentes", considerou que a possibilidade de produzir uma banana resistente à enfermidade, com as características do Gros Michel "valia um esforço significativo". ${ }^{28}$ Nos experimentos efetuados pela Companhia, entre 1925 e 1928 , se cruzaram variedades com contagens distintas de cromossomos, "dos quais, ao se combinarem, podia-se esperar a produção de contagens de cromossomos característicos das variedades comerciais e comestíveis". ${ }^{29}$ Os esforços produziram 14 variedades estéreis, com fruta comestível e sem sementes. No entanto, J.H. Perman, da United Fruit, lamentava que os híbridos tinham pouco valor econômico, dado que, "em nenhum caso, é sua qualidade equivalente às frutas geralmente reconhecidas pelo público como 'bananas'". ${ }^{30}$

A avaliação de Perman, como a de seus contemporâneos britânicos, era um reflexo de como o consumo em massa afetava a criação e recriação da banana de exportação. Produzir uma variedade resistente às enfermidades era só uma parte do desafio: para além, qualquer variedade nova devia assemelhar-se à fruta da Gros Michel.

Em 1930, a United Fruitencerrou seus experimentos no Panamá, e transferiu sua coleção de Musa - consistindo em 81 cultivares partenocárpicos, 27 diplóides com semente, e 26 do tipo bananas da terra - para Lacetilla, 0

27 WARDLAW, Claude W. Diseases of the banana, p.118.

28 PERMAN, J. H. Banana breeding. United Fruit Company Research Department Bulletin, n.21, p.1, 1929.

29 PERMAN, J. H. Banana breeding, p.2-3.

30 PERMAN, J. H. Banana breeding, p.13. 
centro experimental da Companhia, em Tela, Honduras. ${ }^{31} \mathrm{O}$ traslado ocorreu em um momento em que a Companhia estava reduzindo suas operações, em resposta à crise econômica mundial. Além disso, o fracasso da banana Lacatán haveria aumentado as dúvidas acerca da possibilidade de se desenvolver um híbrido. Finalmente, os diretores e acionistas da United Fruit não tinham razão alguma para duvidar que as vastas concessões da Companhia assegurassem uma reserva de terrenos livres de enfermidades - ao menos para o futuro próximo.

Incapaz de encontrar um substituto aceitável para a Gros Michel, a Companhia optou por abandonar os terrenos infectados, em favor de terrenos livres de enfermidades. A julgar pelos padrões de uso da terra, por parte da Companhia, em Honduras, esses freqüentemente se traduziram em índices acelerados de desmatamento e drenagem excessiva dos terrenos úmidos.

Durante dos anos de 1930, a combinação do Mal do Panamá com os conflitos de trabalho, e a crise econômica mundial fizeram com que a United Fruit abandonasse divisões inteiras, na América Central, entre elas suas operações no litoral atlântico de Costa Rica e no departamento de Olón, Honduras. Na Costa Rica, Guatemala e Panamá, a Companhia abriu novas operações, em regiões de terras baixas, do lado Pacífico do istmo. Neste momento, a United também começou a investir no Equador. No total, a Companhia abandonou ao menos 50.000 hectares de fincas, nas terras baixas da vertente atlântica da América Central, antes de 1960. Mas, o sistema de cultivo intensivo, não sustentável, e a evasão permitiram 0 desenvolvimento do Mal do Panamá.

A quantidade aparentemente infinita de terras acessíveis à United Fruit contrastava com as condições do Caribe Britânico, onde tanto o capital, quanto a terra eram escassos. Esta diferença ajuda a explicar por que os britânicos mantiveram seus programas de pesquisa, ao largo dos anos de 1930, e por que a United Fruit não o fez.

Nestes anos, a situação dos produtores de banana jamaicanos se agravou, principalmente pela eclosão de uma segunda epidemia, a Sigatoka. 0 patógeno aéreo, associado à Sigatoka (Mycosphaerella musicola Leach), se disseminava muito mais rápido que o fungo terrestre, associado ao Mal do Panamá. As plantas enfermas de Sigatoka freqüentemente produzem um cacho completo, mas as bananas se suavizam e tendem a amadurecer depressa demais para que a fruta consiga chegar aos mercados internacionais, em condições saudáveis. Em 1936, os técnicos da United Fruit, em Honduras, desenvolveram um sistema de controle baseado na aplicação repetida de um grande volume do "caldo bordolês" (sulfato de cobre),

31 ROWE, Phillip; RICHARDSON, D.L. Breeding bananas for disease resistance, p.7. 
irrigação realizada através da instalação permanente de tubulações nos campos, com sistema de bombeamento, campos. ${ }^{32}$ Esse sistema provia proteção adequada às bananas, quando aplicado com freqüência (10 a 26 vezes por ano), mas o uso intensivo de capital e de trabalho obrigou a muitos produtores de baixa escala a largar a produção. Além disso, esse método gerou um ambiente desagradável e potencialmente nocivo para os trabalhadores rurais. ${ }^{33}$

$\mathrm{Na}$ J amaica, os efeitos da Sigatoka e do Mal do Panamá, junto com as restrições para o embarque, durante a Segunda Guerra Mundial, conduziram a um declive da área cultivada de banana, que caiu de 77.000 hectares, em meados dos anos 1930, para 24.000 hectares, em 1947. Nesta época, os terrenos livres do Mal do Panamá se tornavam tão escassos a tal ponto de dificultar a manutenção de populações de plantas sãs necessários aos experimentos de reprodução realizados pelos pesquisadores do governo.

Contudo, a produção jamaicana logo se recuperou, graças a importantes alterações nas estruturas comerciais então predominantes. Como resultado do acordo de Ottawa, em 1932, as "bananas produzidas no Império" e exportadas para o Reino Unido receberiam um subsidio, o que instou aos agricultores e exportadores da J amaica e das Ilhas Barlovento a reorientar seu comércio, dos Estados Unidos, para o Reino Unido. Em 1938, 83\% das bananas importadas no Reino Unido eram originárias da J amaica. ${ }^{34}$

Após o término da Segunda Guerra Mundial, o Ministério dos Alimentos monopolizou a importação de bananas. E, em 1947, o Ministério aprovou a importação de banana Lacatán, a mesma que havia sido rechaçada pelos mercados norte-americanos, durante os anos 1920. Em 1953, 40.000 hectares do território jamaicano eram cobertos por bananais. ${ }^{35} \mathrm{Na}$ J amaica, portanto, a adoção da Lacatán não foi induzida por um avanço no cultivo, mas sim por mudanças nas condições segundo às quais se produzia e comercializava a banana. ${ }^{36}$

32 Alguns cientistas com base em J ava e Fiji foram os primeiros a fazer uma descrição da Sigatoka, no início do século XX. Pesquisas iniciais, em Fiji, indicaram que o sulfato de cobre podia controlar o patógeno. Desta forma, quando a Sigatoka chegou aos trópicos americanos, na década de 1930, os cultivadores de banana se ocuparam principalmente em gerar formas de se aplicar o sulfato de modo eficiente.

33 Um trabalho recente sobre a enfermidade da Sigatoka é J ONES. (ed.) Diseases of banana, p.79-91. Sobre 0 impacto do sistema de aplicação do caldo bordolês, nos trabalhadores, ver SOLURI, J ohn. Landscape and livelihood: an agroecological history of export banana growing. In: Honduras, 1870-1975. University of Michigan, 1998, p.325-379. (tese de Doutorado); MARQUARDT, Steve. One down!: parakeets, pesticides, and Unions in the Central American banana industry. (palestra apresentada na American Society of Environmental History Conference, Tacoma, Washington, 15-19 de março de 2000).

34 GROSSMAN, Lawrence. The political ecology of bananas: contract farming, peasants, and agrarian change in the Eastern Caribbean. Chapel Hill: University of North Carolina Press, 1998, p.38.

35 RODRÍGUEZ, D.W. Bananas, p.19.

36 Há que se lembrar que os posseiros descritos no princípio deste trabalho buscavam cultivar a Lacatán, em 1928. Antes disso, a variedade era popular nas Filipinas. 


\section{Os programas de fitomelhoramento, 1950-1970}

A mudança dos padrões, na época do pós-guerra, não fugiu à atenção dos pesquisadores britânicos. Em 1951, Norman Simmonds, e seu colega Richard Baker, notaram que a aceitação, pelo mercado, da variedade Cavendish, conduzia ajustes nos objetivos do fitomelhoramento: "agora que os padrões caíram e a Lacatán é aceitável para o comércio, o I.C.2, provavelmente, seria um êxito comercial". "Os objetivos mínimos" de um programa de reprodução - acrescentaram os autores - "podem, portanto, limitar-se à produção de uma banana de qualidade equivalente à Lacatán, mas resistente à Sigatoka; ou uma tão resistente às enfermidades quanto a I.C.2, mas de melhor qualidade. A 'banana ideal' continua sendo uma com as características da Gros Michel, mas resistentes às duas enfermidades".,77

Em sua monografia sobre a banana, em 1959, Simmonds comparava as propriedades de comercialização e transporte da variedade Lacatán, com as da Gros Michel:

Ao amadurecer, a Gros Michel se cobre de um amarelo profundo. A Lacatán tem um tom mais claro e menos atrativo - há que se ter em mente que a fruta dos membros do grupo Cavendish, ao amadurecer tropicalmente, tem o distintivo de serem da cor verde. Quanto ao sabor, a Lacatán não é de nenhum modo, inferior à Gros Michel, e assim se confirma o julgamento de degustadores que se estabeleceram na Inglaterra, há anos, para avaliar os resultados de alguns embarques de experimentos. Entretanto, só se pode asseverar isto ao se tratar da Lacatán de boa qualidade, a que foi cuidadosamente amadurecida. Consta que a média da qualidade da Lacatán amadurecida na Inglaterra é mais baixa que a da Gros Michel. A causa disto é da suscetibilidade da Lacatán ao apodrecimento causado porfungos, durante o transporte. Em textura, a Gros Michel é superior (para a maior parte dos gostos) à Lacatán, pois esta tem um 'corte' levemente mais seco e granulado. ${ }^{38}$

A ênfase aqui colocada nas qualidades estéticas indica que o tema da comercialização continuava sendo tão prioritário, no final dos anos de 1950, como em 1920. Simmonds terminou concluindo que a Lacatán representava "o mínimo em cada uma de suas qualidades, com exceção a resistência às enfermidades". ${ }^{39}$ No entanto, em outro momento, ele comentou que a preferência dos consumidores "provavelmente poderia ser educada" para que aceitassem variedades cujos sabores e texturas diferissem um pouco da Gros Michel. Simmonds, portanto, reconhecia que nem os processos de produção, nem o gosto dos consumidores, eram imutáveis; muito embora 
se mantivesse uma idéia fixa acerca da banana ideal, que seguiria moldando o fitomelhoramento, até os anos 1950.

Após o final da Segunda Guerra Mundial, um novo esquema de investigação fundiu os programas de pesquisa da J amaica e Trinidad, e proveu financiamento para uma expedição de coleta à Ásia. Mas, "considerações políticas", em 1948, findaram por obrigar a equipe de investigação britânica a levar a cabo uma expedição mais reduzida, ao Leste da África. A viagem produziu duas variedades diplóides, que logo foram incorporadas aos experimentos reprodutivos.

Seis anos mais tarde, o Colonial Office financiou uma expedição ao Sudeste da Ásia e ao Pacífico Ocidental, incluindo Samoa, Austrália, Papua Nova-Guiné, Malásia, Tailândia e Índia. Outras áreas, incluindo a Indonésia e Burma, foram deixadas de fora do itinerário por "razões políticas". ${ }^{40}$ De acordo com Simmonds, a viagem tinha dois objetivos principais: "10. descobrir e coletar variedades silvestres e comestíveis de Musa acuminata, aquelas que por sua forma de cacho, tamanho da fruta e resistência a enfermidades pudessem servir no fitomelhoramento da banana; e $2^{\circ}$. conseguir toda a informação científica acerca das bananas, tanto silvestres, quanto cultivadas (...) tanto para melhorar o conhecimento básico sobre o grupo, como para enfrentar problemas práticos futuros". ${ }^{41}$

Tais objetivos refletem a adesão dos pesquisadores britânicos à estratégia baseada em cruzar polinizadores diplóides "melhorados", com a Gros Michel, para produzir tetraplóides.42 Por conseqüência, o objetivo principal da expedição de 1954 foi coletar variedades, com semente e sem semente, de M. acuminata, que pudessem ajudar a melhorar a qualidade dos polinizadores diplóides usados para fertilizar a Gros Michel.

Durante a viagem de oito meses, Simmonds encontrou espécies de Musa em uma ampla gama de ambientes, que variavam em termos de altitude, clima, solos e grau de cultivo humano. Atravessou cordilheiras de montanhas, vales fluviais, sopés de colinas, savanas e bosques. Simmmonds reportou uma tendência de se encontrar Musa em campos abertos: vales desmatados, colinas ensolaradas e leitos de rios. Na Malásia, coletou bananas em algumas colinas "entregues, em grande parte, ao caucho"; uma descrição imprecisa que, no entanto, indica que a área fazia parte de um sistema de manejo agro-florestal. ${ }^{43} \mathrm{O}$ encontro de um cultivo popular,

40 SIMMONDS, Norman W. A banana collecting expedition to South East Asia and the Pacific. Tropical Agriculture, n.33, p.251, 1956.

41 SIMMONDS, Norman W. A banana collecting expedition, p.252.

42 A proliferação da Sigatoka não levou à mudança nesse enfoque, posto que as amostras indicavam que a maioria das variedades diplóides com semente eram resistentes tanto à Sigatoka, quanto ao Mal de Panamá. Ao mesmo tempo, a aceitação de variedades Cavendish nos mercados britânicos não conduziu ao seu emprego nos experimentos reprodutivos, pois estes se mostraram estéreis e raramente produziam sementes, quando cruzados com diplóides.

43 SIMMONDS. A banana collecting expedition, p.262. 
como a banana, próximo a assentamentos humanos e em áreas agrícolas não é de se estranhar, mas sugere que devemos entender as viagens de coleta mais com um tour por diversos ecossistemas agro-ecológicos, que uma expedição a "áreas tropicais remotas".

Entre os materiais que Simmonds coletou, estavam "variedades silvestres" de Musa acuminata de Samoa, Queensland, Papua Nova-Guiné e da Malásia. Mas, uma coisa era coletar germoplasma no sudeste asiático, outra muito diferente era transportá-lo e estabelecê-lo no Caribe. Simmonds mand ou amostras de sementes e brotos a Kew Gardens, onde foram estudados e postos em quarentena, antes de serem transferidos para Trinidad, a fim de serem cultivados em viveiros e campos experimentais.

Em 1956, mais da metade da coleção já havia chegado ao Imperial College, mas muitas das plantas não se adaptaram ao novo meio. Simmonds descreveu os estados de alguns diplóides sem semente, recolhidos na Malásia e em Papua Nova-Guiné, como "muito variáveis". Algumas sementes estavam "excelentes", mas "muitas" morreram e outras eram, ainda, suscetíveis à Sigatoka. Muitas das amostras coletadas em altitudes elevadas pareciam "mal adaptadas" aos ambientes das terras baixas.

Não havia nada de incomum nas diversas variedades de amostras coletadas por Simmonds; espécies introduzidas de Musa usualmente não se desenvolvem nos ambientes caribenhos. Em 1960, 585 espécimes introduzidos haviam sido registrados na coleção do Imperial College, dividindo-se mais ou menos eqüitativamente entre material de plantas e sementes. Só 47 rizomas silvestres sobreviveram, os quais representavam 13 espécies. Essas perdas se devem a vários fatores, entre eles o fato de que mais da metade das sementes não germinara. Muitas das sementes germinadas, particularmente aquelas coletadas em ambientes de altitude, resultaram em plantas débeis ou que se desenvolviam apenas por curtos períodos de tempo. Outras sucumbiram ao Mal do Panamá ou à estação seca de Trinidad. Enfim, em 1960, o Imperial College abrigava cerca de 60 cultivares distintos (incluindo variedades com e sem semente). ${ }^{44}$

Na América Central, a estratégia de cultivo intensivo, não sustentável, e o traslado contínuo da produção havia chegado ao limite de sua utilidade. Só em Honduras, a Companhia havia abandonado mais de 16.000 hectares, entre 1939 e 1953. Ao enfrentar uma crescente escassez de terras livres do Mal do Panamá, os engenheiros da United Fruit desenvolveram projetos de "reclame de terra" em larga escala, empregando uma série extensiva de

44 Em 1974, o diretor do Banana Breeding Research Écheme, na J amaica, notou que os pesquisadores conseguiram estabelecer "relativamente pouco" do material recolhido no Sudeste Asiático. A expedição contribuiu para que ocorressem grandes revisões na taxonomia da banana. Simmonds e Shepherd desenvolveram um sistema de pontuação, baseado em 15 características de diagnóstico, que conduziu à formulação do atual sistema de classificação das variedades triplóides em três classes. M. acuminata pura (AAA); e M. balbisiana de um terço e de dois terços (AAB, ABB). SHEPHERD, K. Banana research at ICTA. Tropical Agriculture, n.51, p.484, 1974. 
diques, ao largo do Rio Ulúa, para desviar as águas de inundação até os terrenos úmidos, onde sedimentos eventualmente se assentavam.

Um dos maiores projetos de sedimentação empreendidos ocorreu em um sítio de 4.500 hectares, conhecido como El Pantano..$^{45} \mathrm{~A}$ primeira etapa consistia em construir diques, tendo o mais largo destes uma extensão de quase oito quilômetros, com 3 a 4 metros de profundidade. Em 1947, a Companhia drenou a terra utilizando uma bateria de bombas impulsionadas por turbinas, removendo a água e assegurando que o nível freático não se elevasse a níveis inaceitáveis (tarefa difícil, em se tratando de uma terra baixa, situada entre dois rios).

O processo de sedimentação produziu um beneficio que não havia sido previsto pela United Fruit: os cientistas observaram que os terrenos, após acumular sedimentos durante várias estações chuvosas, produziam "fruta de primeira" por vários anos. ${ }^{46}$ Isto inspirou um pesquisador da United Fruit, Vinig Dunlap, a iniciar, em 1939, uma série de experimentos de inundação de pousios, orientados para recuperar os terrenos infectados com o Mal do Panamá. ${ }^{47}$ Dunlap supervisionou a construção de lagos artificiais, que permaneceram cheios de água por períodos de tempo variáveis (de 3 a 8 meses). Em 1953, em Honduras, cerca de 5.700 hectares haviam passado por esse processo de inundação de pousios, e foram replantados com rizomas de Gros Michel livres de patógenos. Os projetos de drenagem e inundação demonstram a sofisticada destreza da engenharia da Companhia, mas, também, evidenciam o incremento, em custos financeiros e ecológicos, associados ao cultivo de banana nesses terrenos, que antes haviam sido terras úmidas com grande variedade de flora e fauna. ${ }^{48}$

A Standard Fruit Company também realizava experimentos de inundação de pousios, em Honduras. No final dos anos de 1940, a Standard Fruit estava perdendo entre 10 e $15 \%$ de suas terras produtivas, por ano. Em 1947, os altos executivos da Standard decidiram arrendar 7.500 hectares de terreno nacional, no lado norte do Rio Aguán, para proceder a inundação de

45 A seguinte descrição do projeto El Pantano está em United States National Archives, U.S. Foreign Agricultural Service (RG 166), "Narrative Reports, 1946-49", Entry 5, Box 743. DE GRAHAM S. QUATE, Embajada Americana, Tegucigalpa, Reporte no. 245, "The Agricultural Operations of the Tela RR Company", 17 de setiembre de 1947, 6-8.

46 No transcurso de um período de cinco ou mais anos, a sedimentação podia produzir solos de vários pés de profundidade. Durante o processo, os terrenos raramente se permaneciam cobertor de água por mais de três semanas, por vez. Entre as inundações, crescia "uma vegetação densa, com ervas e arbustos", que cobria os terrenos, dotando-os de grandes depósitos de material orgânico. Este padrão de barbecho seco, inundações periódicas e depósitos de sedimentos parecia diminuir as populações de patógenos o suficiente para que se permitisse alguns anos de cultivo de Gros Michel. Ver STOVER, Robert H. Fusarial wilt (Panama disease) of the banana and other Musa species. Kew/Inglaterra: Commonwealth Mycological Institute, 1962, p.96; UNITED FRUIT COMPANY. Problems and progress in banana disease research. Boston: United Fruit Company, 1958, p.4-6.

47 UNITED FRUIT COMPANY. Division of Tropical Research, Annual Report, p.2, 1939.

48 Para uma descrição do impacto da destruição de terrenos úmidos na flora e fauna local, ver PETERS, J ames L. An ornithological survey in the Caribbean lowlands of Honduras. Bulletin of the Museum of Comparative Zoology, p.397-399, 1929. 
pousios ${ }^{49} \mathrm{O}$ terreno, que já havia sido cultivado e abandonado pela United Fruit, era considerado como o único lugar no vale com água suficiente para executar tais planos em larga escala. Contudo, a companhia deteve seus experimentos, companhia deteve seus experimentos, no começo da década de 1950, devido ao seu alto custo. ${ }^{50}$

Em seu lugar, a administração da Standard Fruit decidiu buscar uma banana resistente à enfermidade que pudesse substituir a Gros Michel. Desde meados dos anos de 1940, a Standard realizou provas com diversas variedades, iniciando seus experimentos com o I.C.2 (provido pelo Imperial College), o Bout Rond (uma variedade Cavendish, que Simmonds considerava ser a mesma que a Lacatán), e o Cavendish Gigante (um cultivar Cavendish do Brasil). ${ }^{51}$ A Standard embarcou modestas quantidades de I.C.2, entre 1944 e 1954, mas, o pequeno cacho desta variedade, e suas pencas, de frutos curtos, encontraram pouca aceitação nos mercados norte-americanos, um resultado que deve ter decepcionado Simmonds e seus colegas do Imperial College.

A administração da Standard estava mais otimista com respeito ao potencial de comercialização da Bout Rond e do Cavendish Gigante. Ainda que nenhuma das variedades amadurecesse como a Gros Michel, elas desenvolviam "bananas muito bonitas", sob temperaturas apropriadas e a exposição ao gás etileno..$^{52} \mathrm{~A}$ companhia eventualmente converteu todos os seus cultivos à Cavendish Gigante, uma vez que esta variedade oferecia maiores rendimentos e era menos suscetível ao vento que a Bout Rond. ${ }^{53}$ Inicialmente, as exportações de Cavendish da Standard tiveram que enfrentar altos índices de rechaço e desconto, nos mercados norte-americanos, devido à facilidade com que sua delicada casca se avariava. Mas, a Standard superou este problema através de uma inovação tecnológica: o empacotamento das bananas em caixas de papelão antes de embarcá-las. Esse fato estimulou uma série de mudanças sociais e ecológicas, e o novo processo de produção ajudou a assegurar um mercado para as variedades Cavendish resistentes ao Mal do Panamá.

A United Fruit continuou produzindo e exportando a Gros Michel, ao longo dos anos 1950, mas, em meados da década, cerca de $50 \%$ da produção hondurenha vinha de terras de inundação de pousios, um indicador

49 STANDARD FRUIT COMPANY. Memorandum of Conference held in the board room on the afternoon of J anuary 3, 1947, for discussion of various matters concerning our Honduras and Nicaragua Divisions, 1. Standard Fruit and Steamship Company Papers, Howard-Tilton Memorial Library, Tulane University.

50 MUERY, Henry O. Historical overview (manuscrito mecanografado, 17 de maio de 1984), p.1. Agradeço a J osé P. Sánchez de La Ceiba, Honduras, por me prover uma cópia deste documento inédito sobre as pesquisas da Standard Fruit.

51 Simmonds considerava a Lacatán e a Bout Rond como uma mesma variedade. Ela classificava as variedades Lacatán/Bout Rond e Cavendish Gigante como membros do grupo Cavendish.

52 P.C. Rose a S. D'Antoni, 24 de setiembre de 1943, 2; y A.J. Chute a P.C. Rose, 6 de mayo de 1944. Standard Fruit and Steamship Company Papers, Howard-Tilton Memorial Library, Tulane University.

53 "Giant Cavendish" era uma denominação enganosa; a planta era mais baixa que a Gros Michel e a Bout Rond. 
de quão escassos haviam se tornado os terrenos livres de patógenos. Mas, os administradores tradicionais consideravam que substituir à Gros Michel por outra variedade seria uma traição aos padrões de qualidade da Companhia. ${ }^{54} \mathrm{O}$ entusiasmo pelo método de inundação de pousios começou a diminuir, quando os investidores da Companhia reportaram que a prática só podia assegurar cinco anos de produção, antes que o Mal do Panamá retornasse..$^{55} \mathrm{Em} \mathrm{1957,} \mathrm{o} \mathrm{diretor} \mathrm{de} \mathrm{pesquisas} \mathrm{da} \mathrm{Companhia,} \mathrm{Dr.}$ J.E. Hobson, observou que a Companhia já não podia "fugir dos problemas mudando-se para novos terrenos". ${ }^{56}$ Em 1959, depois de vários anos de experimentos de inundação, o patologista de plantas da United Fruit, Robert Stover, escreveu que o melhoramento genético da banana era "a única estratégia com esperanças, a longo prazo, para solucionar os problemas das enfermidades das bananas". ${ }^{57}$ Neste mesmo ano, a divisão de pesquisa instituiu um departamento de Reprodução de Plantas e Genéticas. ${ }^{58}$

Uma das primeiras ações do departamento foi aumentar sua coleção de material reprodutivo. A Companhia contratou os botânicos Paul Allen e J J. Ochse para conduzir viagens ao Sudeste Asiático e ao Pacífico Ocidental, com o fito de coletar novas fontes de germoplasma. ${ }^{59} \mathrm{Em}$ setembro de 1959, Paul Allen viajou às Filipinas, onde recebeu o apoio do Colégio de Agricultura de Los Baños. Dois meses mais tarde, Dorothy Allen - esposa de Paul e ilustradora botânica - e um pesquisador da United, David Cloward, se uniram a Paul Allen. Apesar de raramente ser reconhecida nas publicações científicas, Dorothy Allen parece ter desempenhado um papel crucial na documentação, limpeza e empacotamento das aquisições. ${ }^{60} \mathrm{Em}$ uma carta a Wilson Popenoe, Paul Allen descreveu seu trabalho nas Filipinas como "uma busca de rio a rio, de montanha a montanha, e de ilha a ilha" para obter sucesso na coleta de uma mostra significativa de aquisições com propósitos reprodutivos. ${ }^{61}$ Acrescentava que, após cinco meses de trabalho, ela e seus companheiros havia registrado cerca de 500 nomes comuns para

54 ARTHUR, Henry B.; HOUCK, J ames P.; BECKFORD, G. Tropical agribusiness structures and adjustments - bananas. Boston, 1968, p. 149. Ver também o memorando do executivo de relações públicas da United Fruit Company, publicado em MCCANN, Thomas P. An American company: the tragedy of United Fruit. Nova York: Crown Publishers, 1976.

55 STOVER. Fusarial wilt of bananas, p.97.

56 UNITED FRUIT COMPANY. Research meetings: summary of discussions and reports, n.29-31, de agosto de 1957 (FHIA Pamphlet 6603), p.4.

57 UNITED FRUIT COMPANY. Division of Tropical Research. Research Extension Newsletter, 6, n.4 (novembro de 1959), p.10.

58 UNITED FRUIT COMPANY. Division of Tropical Research. Annual Report, 1959.

59 Aparentemente, a expedição dirigida por Ochse trabalhou principalmente em Papua Nova-Guiné. No entanto, ainda não foram encontradas fontes que descrevam a rota das expedições, e seus sucessos. Para uma menção de papel desempenhado por Ochse na recolecção de Musa, ver ROSALES, Franklin; ARNAUD, Elizabeth; COTO, J ulio. (eds.) A tribute to the work of Paul H. Allen: a catalogue of wild and cultivated bananas. Montpellier, França: International Network for the Improvement of Banana and Plantain, 1999.

60 Ver: Dorothy Allen a Wilson Popenoe, 25 de febrero de 1961, Hunt Institute for Botanical Documentation Archive, Carnegie Mellon University, Pittsburgh, Pennsylvania, E.E.U.U. (doravante, HIBD), Wilson Popenoe Collection, Correspondência.

61 Paul H. Allen a Wilson Popenoe, 21 de febrero de 1960, HIBD, Wilson Popenoe Collection, Correspondência. 
bananas, e 150 variedades, quantidades consideravelmente maiores do que Simmonds havia reportado para as Filipinas, na sua então recém publicada monografia sobre bananas. No total, os Allen passaram vinte e sete meses coletando, processando e embarcando espécimes de Musa.

Allen, como Simmonds, dedicou muito tempo coletando em ambientes muito perturbados. Por exemplo, em uma carta em que descreve seus achados iniciais, Allen notou que as bananas tendiam a "substituir nossas Heliconas [centro-americanas], no esquema ecológico, mas, agora, raras vezes eram encontradas, exceto em terrenos cercados e próximos a populações humanas". ${ }^{62}$ Alguns meses mais tarde, a equipe de Allen viajou para a cidade de Kuala Lumpur, na Malásia, "onde coletaram tantas sementes e estacas, que cuidar do material quase esgotou a todos". ${ }^{63}$ Ainda que estas descrições seja imprecisas, sugerem claramente que as variedades da espécie Musa eram encontradas em terrenos que haviam sido moldados pelas atividades humanas - incluindo grandes áreas urbanas, como Kuala Lumpur. As aquisições coletadas durante as expedições eram, então, tanto artefatos culturais (na verdade, agriculturais), quanto recursos biológicos.

No final da década de 1950, uma conjuntura de aumento nos índices do Mal do Panamá, saturação do mercado (gerada, em parte, pelo dramático aumento nas exportações do Equador), custos laboratoriais crescentes e problemas legais internos produziu uma forte redução nos dividendos anuais da United Fruit, e no valor de suas ações. ${ }^{64}$

Em 1959, Thomas Sunderland substituiu o veterano Kenneth Redmond, no posto de gerente executivo. ${ }^{65}$ Notando que o Mal do Panamá custava milhões de dólares por ano à Companhia, Sunderland ordenouo aumento da produção de banana Cavendish. ${ }^{66}$ No ano seguinte, o departamento de pesquisas da United Fruit informou o fim dos experimentos com a Gros Michel; transferiam-se, então, as energias do departamento para o exame das variedades de Cavendish (incluindo a Cavendish Gigante, Valery e Grand Nain), na tentativa de se determinar sua resistência às enfermidades e possibilidade de serem embarcadas em caixas de papelão.

Em 1965, a United Fruithavia reconvertido toda sua produção, na América Central, a variedades resistentes ao Mal do Panamá. Tal como haviam feito os cultivadores do Caribe britânico e a StandartFruit Company, a U nited Fruit adaptou suas práticas de produção para poder cultivar variedades Cavendish, já bastante conhecidas em outras regiões tropicais. A Valery,

62 Paul H. Allen a Wilson Popenoe, 21 de febrero de 1960, HIBD, Wilson Popenoe Collection, Correspondência.

63 Dorothy Allen a Wilson Popenoe, 25 de febrero de 1961, HIBD, Wilson Popenoe Collection, Correspondência.

64 Entre 1950 e 1960, as exportações de banana do Equador aumentaram de 8 milhões de racimos até cerca de 36 milhões. SIMMONDS, N.W. Bananas, p.324. No mesmo período, os lucros caíram de \$66 milhões até \$2 milhões, enquanto os preços das ações caíram de $\$ 70$ a $\$ 15$.

65 ARTHUR; HOUCK; BECKFORD. Tropical agribusiness structures and adjustments, p.146.

66 ARTHUR; HOUCK; BECKFORD. Tropical agribusiness structures and adjustments, p.150. 
por exemplo, havia sido coletada em 1925, por Otto Reinking, em Saigon. ${ }^{67}$ Depois de décadas beneficiando-se de um sistema de produção que reduzia severamente a diversidade de plantas a nível local, a United Fruit pode tirar vantagens de uma diversidade pantropical, dentro do gênero Musa, para superar o Mal do Panamá.

Quando de seu regresso a Honduras, em 1961, Paul Allen empreendeu o titânico trabalho de catalogar e estudar as quase 700 aquisições, um projeto inconcluso devido a sua morte causada por um câncer, em $1963 .{ }^{68}$ Neste momento, a coleção incluía Musa de pelo menos dezessete paises, mas a maior parte do material vinha da Indonésia, Malásia, Papua Nova-Guiné e Filipinas. Entre 1965 e 1975, os programas de reprodução da United Fruit - tirando proveito da coleção de Musa mais extensa do mundo - desenvolveram linhas "superiores" de diplóides. Esses híbridos combinavam resistência a enfermidades com rendimentos altos e fenótipos próximos aos padrões desejados. Identificar a resistência às enfermidades entre diplóides resultou ser relativamente simples, mas muitos deles produziam cachos muito pequenos ou, por alguma outra razão, não atingiam as exigências do mercado. ${ }^{69}$

Um diplóide híbrido particularmente prometedor surgiu entre os cruzamentos com as aquisições de Papua Nova-Guiné, J ava, Malásia e das Filipinas: esse é outro exemplo de como os fitomelhoramentos comerciais, na América Central, utilizaram a diversidade de Musa presente em todo o mundo tropical. ${ }^{70}$

Posteriormente, os fitomelhoramentos da Companhia utilizaram diplóides híbridos em cruzamentos com a Highgate (uma mutante anã da Gros Michel, da J amaica), e outros diplóides. A reprodução da banana continuou sendo um processo lento: durante os anos de 1960, trabalhadores da United Fruit costumavam cultivar entre 10.000 e 20.000 plântulas diplóides híbridas, por ano, para empreender avaliações substantivas de seu fenótipo. Sintetizar e realizar experimentos com diplóides levava, em média, três anos. Na década de 1970, os pesquisadores utilizavam linhas de diplóides, sintetizados em cruzamentos com a Highgate, para produzir tetraplóides primários. Em alguns casos, os tetraplóides híbridos alcançavam maiores rendimentos que as variedades de exportação Cavendish, tal como a Valery, mas tendiam a alcançar uma menor duração nas vitrines, além de outros defeitos de comercialização. Ironicamente, novos padrões, promovidos pela conversão às variedades Cavendish, fizeram com que

67 ROWE, Phillip; RICHARDSON, D.L. Breeding bananas for disease resistance, p.7-8.

68 Paul Allen a Wilson Popenoe, 3 de diciembre de 1961, HIBD, Paul H. Allen Papers, Box 2.

69 Os pesquisadores identificaram resistência às raças de fusarium 1 e 2 , e a Sigatoca, na M. acuminata subespécie malaccensis y burmannica. Resistência aos nemátodos perfuradores foi encontrada na Pisamg jari buaya, do grupo M. acuminata.

70 ROWE, Phillip; RICHARDSON, D.L. Breeding bananas for disease resistance, p.28. 
alguns dos híbridos produzidos pelos programas de fitomelhoramento se tornassem obsoletos, nos anos 60, ainda que houvessem sido aceitos nos mercados de exportação, na era anterior à do Cavendish. ${ }^{71}$

Em 1984, a administração da United Brands (antiga United Fruit), aparentemente frustrada com o fato de que vinte e cinco anos de pesquisa não haviam rendido uma única variedade comercializável, doou seu programa de melhoramento à Fundación Hondurenha de Investigación Agńcola (FHIA), em La Lima, Honduras. Com o financiamento de agências internacionais, a agenda da FHIA havia se expandido, incluindo variedades de bananas de interesse para os próprios residentes dos trópicos. Na ultima década, a FHIA começou a produzir resultados tangíveis, partindo dos esforços de décadas passadas no tocante ao melhoramento de diplóides. Hoje, um punhado de híbridos tetraplóides da FHIA, incluindo um com resistência tanto para o Mal do Panamá, como para a Sigatoka, estão sendo produzidos para os mercados domésticos do Brasil, Caribe, e América Central. ${ }^{72}$

Entre 1960 e 1980, pesquisadores, na J amaica, levaram a cabo uma extensiva gama de experimentos de melhoramento genético, utilizando a Highgate e diplóides sintetizados. ${ }^{73}$ Os esforços produziram vários tetraplóides resistentes ao Mal do Panamá e à Sigatoka. Grupos de catadores descobriram que as novas bananas eram comparáveis aos clones de Cavendish quanto ao sabor, mas os tetraplóides mostraram ter uma durabilidade consideravelmente menor do que se considerava necessário para um bom desempenho comercial, nos mercados britânicos. Ainda que o programa britânico tenha fracassado em produzir uma banana aceitável para o mercado de exportação, os reprodutores criaram de variedades que possuíam várias gradações de resistência aos patógenos. Este resultado deveu-se, em grande parte, à capacidade dos cientistas em recorrer à diversidade genética contida nas aquisições de Musa acuminata que haviam sido recoletadas em Bornéu, Índia, Malásia, Samoa e Zanzibar. ${ }^{74}$

71 As variedades Cavend ish eram mais baixas e produziam maiores rendimentos que a Gros Michel. Por isso, quando os cientistas da United Fruit produziram uma planta tetraplóide resistente à Sigatoka e ao Mal de Panamá, e cuja fruta era como a da banana Gros Michel, os pesquisadores não consideraram sua criação comercialmente viável, devido à sua "alta" estatura, em comparação com outras plantas, e a seus "baixos" rendimentos.

72 Agências internacionais que provêem fundos começaram a apoiar projetos que empregam biotecnologia para dotar de resistência a enfermidades, mas a pesquisa ainda se encontra em etapas muito iniciais. Para um resumo atualizado tanto do "cultivo convencional", como da emergente engenharia genética e seus programas, ver: ROWE, Phillip; ROSALES, F.E. Conventional banana breeding in Honduras. SÁGI. Genetic engineering of banana for disease resistance - future possibilities. In: J ONES, David R. (ed.) Diseases of banana, p.435-495.

73 Em 1960, uma nova versão do Banana Breeding Research Scheme consolidou as atividades fitoreprodutivas, na J amaica, e encerrou os 38 anos de atividade do Imperial College, em Trinidad. Cientistas filiados com o Imperial College publicaram dois livros, que se converteram em clássicos, durante esse período: WARDLAW, Claude. Diseases of the banana; SIMMONDS, N.W. Bananas.

74 SIMMONDS, N.W. Bananas, p.421-422. 


\section{História, biologia e cultura: as distâncias enganam}

A história dos programas de fitomelhoramento da banana, no século $X X$, é especialmente notória naquilo que oitenta anos de esforço científico fracassaram em produzir: uma banana híbrida com "qualidade de exportação". Os obstáculos enfrentados pelos cientistas, ao largo desses esforços de investigação sobre o melhoramento da banana, nunca foram puramente genéticos: a esses obstáculos há que se acrescer tanto os de ordem ecológica e econômica, quanto os processos culturais que perfilaram (e, amiúde, restringiram) as visões cientificas da banana de exportação.

Argumentamos que uma relação dinâmica entre os mercados de consumo em massa e os processos de produção instigaram e modelaram os programas institucionais de reprodução. Tanto os britânicos, quanto os norte-americanos iniciaram experimentos em fitomelhoramento, em resposta ao Mal do Panamá. A importância histórica do Mal do Panamá (e, logo, da Sigatoka) decorreu das estruturas e sensibilidades estéticas dos mercados de massa, que criaram obstáculos para a adoção de variedades conhecidas, resistentes aos patógenos. Quando os cultivadores de banana do Caribe e da América Central começaram a substituir a Gros Michel por variedades mais resistentes às enfermidades, não introduziram híbridos: utilizaram, sim, cultivares Cavendish, uma variedade endêmica do Sudeste Asiático, cujo desenvolvimento foi produto dos esforços de cultivadores locais, ao longo de muitos séculos. E, na realidade, as origens da exportação moderna de banana se estendem através dos continentes, até um passado pré-moderno.

Nossa meta, nestas páginas, não foi o de apresentar Allen, Simmonds, e os outros botânicos que coletaram Musa, durante o século passado, como exploradores das populações indígenas. Mas, sim, chamara atenção para o fato de que a literatura científica sobre o melhoramento genético tende a assumir que o material botânico é um "recurso natural" sem uma história que o una a lugares e povos particulares.

Há mais de três décadas, alguns estudiosos têm insistido na importância dos intercâmbios continentais de plantas e animais, uma mescla da biota que continua ocorrendo. ${ }^{75}$ Mas, atualmente, o tema merece uma nova ênfase, ante o futuro incerto das zonas ecológicas tropicais. Muitas instituições científicas e de desenvolvimento contemporâneas criam projetos cujos objetivos se articulam através de um discurso sobre "biodiversidade global" e "segurança planetária", que tende a tornar óbvios os nexos históricos entre recursos biológicos específicos, lugares particulares e contextos culturais. Os esforços internacionais para se estabelecer, e manter, coleções centrali-

75 Alfred Crosby é, talvez, o estudioso a quem mais freqüentemente se credita a mudança de enfoque dos historiadores sobre este tema, realizada através de sua obra clássica, de 1972: CROSBY, Alfred. The Columbian exchange: biological and cultural consequences of 1492. Westport/Connecticut: Greenwood Publishing, 1972. 
zadas (exsitu) de germoplasma de plantas cultivadas partem da separação entre cultivador e cultivo. Essa maneira de abordar o conservacionismo nega a possibilidade de se revestir de igual importância o conhecimento sobre os agroecossistemas nos quais as plantas evoluíram, de modo a se entender o genótipo e o fenótipo de uma variedade específica. ${ }^{76}$

A história do fito-melhoramento da banana de exportação questiona fortemente a validade de tais enfoques, demonstrando a importância de se situar os organismos em um amplo contexto agroecológico, econômico e cultural, capaz de revelar as conexões - às vezes ocultas - entre produção e consumo, entre sociedades "tradicionais" e "modernas", entre natureza e cultura. Por esta razão, necessitamos de estruturas e metodologias que aceitem perspectivas pantropicais, sem perder a capacidade de enfocar, em nível micro, as interações entre as pessoas, as plantas e os demais organismos. De outra maneira, corre-se o risco de que visões "globais" da biodiversidade inadvertidamente dissociem a biologia da cultura, os cultivos dos cultivadores, e o passado do futuro.

760 armazenamento ex situ é, logisticamente, muito complicado, particularmente para os cultígenos tropicais que não se cultivam a partir de sementes. (Há que se lembrar de quantas aquisições de Musa se perderam, ao longo dos anos de coleções institucionais, em Trinidad e Honduras.) 